\title{
Assessing quality of life and burden of disease in chronic rhinosinusitis: a review*
}

Dionisios Klonaris, Maria Doulaptsi, Alexander Karatzanis, Stylianos Velegrakis, Athanasia Milioni, Emmanuel Prokopakis

Department of Otorhinolaryngology - Head and Neck Surgery, University of Crete School of Medicine, Heraklion, Crete, Greece
Rhinology Online, Vol 2: 6 - 13, 2019

http://doi.org/10.4193/RHINOL/18.067

*Received for publication:

August 28, 2018

Accepted: January 3, 2019

Published: January 9, 2019

\begin{abstract}
Background: Chronic rhinosinusitis has been shown to have a significant impact on patients' quality of life (QoL). We present and summarize current knowledge on assessment methods of Chronic Rhinosinusitis (CRS) burden and QoL.
\end{abstract}

Methodology: Review of the literature using the PubMed database (search of terms "chronic rhinosinusitis", "CRS", "quality of life", "QoL", "outcome measures", "assessment of CRS", "CRS burden" separately or combined) limited to articles published in the English language.

Results: Despite the plethora of objective methods available to assess and quantify burden of CRS, discrepancies are occasionally encountered when correlation with subjective measures of QoL is attempted via numerous patient self-reporting tools.

Conclusion: CRS has a detrimental effect on QoL and assessing disease severity and burden is a difficult goal. The applicability of known assessment methodologies should be re-evaluated and validated according to research findings on CRS pathophysiology, and new tools should be developed based on the emerging knowledge and the need for personalized treatment and evaluation methods.

Key words: chronic rhinosinusitis, QoL, burden of disease, outcome measures, disease-specific QoL questionnaires

\section{Introduction}

Chronic rhinosinusitis (CRS) is a disease characterized by chronic inflammation of nose and paranasal sinuses, with a high prevalence among the USA and Europe. In respect to observable characteristics, CRS is distributed in two major phenotypes, CRS with nasal polyps (CRSwNP) and CRS without nasal polyps (CRSsNP) (1). Disease and its subtypes vary amongst population subgroups, depending on demographic characteristics and co-morbid conditions ${ }^{(2)}$. CRS symptoms have a debilitating effect on productivity and patients' emotional status ${ }^{(3,4)}$. This was shown to be significantly more pronounced in cases with concomitant chronic pulmonary diseases and psychiatric disorders ${ }^{(5,6)}$. Furthermore, disease-associated financial expenses and lost workdays are far from negligible ${ }^{(7)}$. The combination of socioeconomic burden and negative impact on well-being ultimately affects patients' quality of life (QoL) ${ }^{(8)}$.
Diagnosis of CRS is based on a combination of symptoms and objective findings from nasal endoscopy and/or imaging examinations ${ }^{(1)}$. Disease control is defined as a state in which patients do not have symptoms or symptoms are not bothersome, accompanied with a healthy or almost healthy mucosa ${ }^{(1,9)}$. Multiple measures have been utilized to diagnose and assess burden of disease, level of control, response to treatment and, overall QoL. Beside endoscopy, computed tomography (CT) imaging of nose and paranasal sinuses is regularly used to assess disease severity and is always necessary for surgical planning ${ }^{(1)}$. Beside objective measures, a variety of patient rated outcome measures (PROM) are available. These tools can be either generic or disease-specific. The latter one is aiming to evaluate specific aspects of the disease, quantify symptoms severity, and overall to assess QoL ${ }^{(10)}$. Among different disease-specific outcome measure instruments in CRS, the Sino-Nasal Outcome Test 
(SNOT)-22 is widely accepted and has been used in several studies ${ }^{(11)}$. Based on total severity visual analog scale (VAS) score, CRS can be classified into mild, moderate, and severe. A VAS $>5$ is considered to affect patients' QoL (1).

Herein, we present established and new knowledge on assessment tools used in the Rhinology field to evaluate CRS burden and QoL in CRS patients. We performed a review of the literature using the PubMed database (search of terms "chronic rhinosinusitis", "CRS", " "quality of life", "QoL", "outcome measures", "assessment of CRS", "CRS burden" separately or combined) limited to articles published in the English language. Furthermore, we aim to describe published factors which are known to affect patients' QoL, as determined by outcome measures.

\section{Measuring quality of life}

According to the World Health Organization (WHO), health is defined as a "state of complete physical, mental and social wellbeing, and not merely the absence of disease and infirmity" (12). The earliest publications addressing QoL issues appeared in the mid-twentieth century ${ }^{(13)}$ and the first QoL measurement instrument was introduced in $1981^{(14)}$. These terms are not identical and should be distinguished from each other ${ }^{(15)}$, although they are frequently considered and treated as synonymous. It has been advocated that health-related QoL (HRQoL) is a subset of QoL relating only to aspects of health ${ }^{(16)}$, and consists the main target of medical research and rehabilitation. Multiple types of QoL measurements exist: dimension-specific, disease- or population-specific, generic, individualized and utility measures ${ }^{(17)}$. Under this scope, CRS assessment should not be limited to health-related or disease-specific QoL measurements ${ }^{(18,19)}$.

\section{Subjective (psychometric) assessment methods of CRS: scales and questionnaires}

Visual scales

As measurement instruments, visual scales can provide a means for subjective characteristics or attitudes assessment that cannot be directly measured. Respondents specify their level of agreement to a statement by indicating a position along a continuous or discrete scale between two end-points ${ }^{(20)}$. The Visual Analogue Scale (VAS) concept was first described and used in the early 20th century, and since then is widely used in questionnaires. There is evidence showing that VAS have superior metrical characteristics than discrete ones, thus a wider range of statistical methods can be performed on the acquired data ${ }^{(20)}$. Results from a validation study with 355 participants are reported and show that the scales generated with VAS Generator approximate an interval-scale level. In light of previous research on VAS versus categorical (e.g., radio button) scales in Internet-based research, we conclude that categorical scales only reach ordinal-scale level, and thus, VAS is to be preferred whenever possible. VAS is simple, easy to use, does not require training and it has been proved to be a fast and inexpensive method to describe population and group characteristics in the health science field and in clinical practice ${ }^{(20)}$.

\section{The Sino-Nasal Outcome Test (SNOT)}

The SNOT questionnaire has been specifically designed to include symptoms intimately related with rhinosinusitis. The SNOT-20 and SNOT-22 variants are the most widely used and have been proved reliable tools for prediction of post-surgical improvement, as well as outcomes assessment after Endoscopic Sinus Surgery (ESS) ${ }^{(11,21)}$. The SNOT-16 variant has been successfully used to determine the effectiveness of interventions to improve disease-specific QOL in adults with acute rhinosinusitis (22). One of the main advantages of the SNOT-22 is the distribution of symptoms into discrete domains (rhinologic, extra-nasal rhinologic, ear/facial, psychological and sleep). A recent study has demonstrated that scores in different groups of symptoms can differentially predict and guide treatment modality selection in CRS ${ }^{(23)}$. The SNOT-22 has been translated and validated in multiple languages, thus providing a "common ground" for medical cross-communication and a homogenous data pool for multi-center studies and meta-analyses ${ }^{(24-26)}$.

\section{The 36-Item Short Form Survey (SF-36)}

The 36-Item Short Form Survey (SF-36) is a 36-item, patientreported survey of patient health that came out from the Medical Outcome Study (MOS) ${ }^{(27-29)}$. While designed as a generic QoL assessment tool, it has been successfully used to evaluate post-operative outcomes after ESS ${ }^{\left({ }^{30}\right)}$, as well as calculate the health and socioeconomic burden of chronic CRS ${ }^{(4,6,31)}$. Known limitations of this questionnaire are that it does not take into consideration a sleep variable, and has a low response rate in older (>65 years) age groups ${ }^{(32)}$.

\section{Nasal Obstruction and Symptom Evaluation (NOSE)}

The NOSE instrument was originally developed as a disease-specific tool for the assessment of nasal obstruction in patients with nasal septum deformities, as well as other related pathologies (mucosal congestion, turbinate hypertrophy, adenoid hypertrophy, nasal mass, and others) ${ }^{(33)}$. Since its initial conception, it has been used to classify nasal obstruction severity ${ }^{(34)}$, its efficiency has been verified ${ }^{(35)}$, and has been adapted and validated in several language and cultural settings ${ }^{(36)}$. Although its usage is continually expanded for the evaluation and treatment outcomes in diseases affecting the upper airway ${ }^{(37-40)}$, it is not suitable for CRS severity and outcomes measurements ${ }^{(41)}$.

\section{EuroQol 5-Dimensional (EQ5D)}

The EuroQol 5-Dimensional (EQ5D) is a standardized instrument for measuring generic health status, first introduced in 1990 by the EuroQol Group ${ }^{(42)}$. Although a generic QoL assessment 
instrument, it has been successfully used for studying clinical outcomes in CRS ${ }^{(10,43,44)}$. With good validity and reliability, ease of use and wide applicability, it has become one of the most commonly used generic health status measurement tools.

\section{Living with CRS: disease impact on quality of life}

Patients with CRS report impaired QoL in both the physical and mental domains. This negative effect is more pronounced in emotional function, general health, role physical function, female gender, the elderly and subjects with high-level education ${ }^{(45)}$. In another study ${ }^{(46)}$, significantly more reduced HRQoL was identified in female subjects indifferent of CRS phenotype, especially in the anxiety/depression domain, with more prominent findings in the CRSwNP subgroup. Also, worse QoL and diseaseassociated pain in CRS may lead to neurocognitive dysfunction, although the underlying mechanisms have still not been identified ${ }^{(47)}$. Sleep disruption prevalence is significantly higher in CRS patients, and is linked with worse QoL, impaired cognitive function and mood disturbances ${ }^{(48,49)}$. Strangely, CRS-associated smell and taste disturbances do not seem to affect eating-related QoL, while co-morbidities like aspirin-exacerbated respiratory disease (AERD) and depression appear to be independent risk factors ${ }^{(50)}$. This is compatible with the findings of a recent study (41), which identified only a limited association between nasal obstruction assessed with the NOSE instrument and CRS-related QoL. Overall, changes in the sleep and ear/facial domains are shown to be the most greatly associated with QoL ${ }^{(51)}$.

\section{Working with CRS: the hampering effect of reduced quality of life on productivity}

CRS negatively affects multiple aspects of a patient's life, including work productivity, resulting in a high socioeconomic burden. This is attributable to the disease-associated depression symptoms, missed workdays and treatment needs ${ }^{(52,53)}$. Also, facial pain appears to be a significant factor resulting to presentiism ${ }^{(54)}$. The frequency of acute exacerbations of the disease has also been shown to result in reduced productivity in both asthmatic and non-asthmatic patients ${ }^{(55)}$. The overall indirect cost due to CRS-related work productivity loss in the USA has recently been estimated to be over 20 billion dollars per annum ${ }^{(56)}$.

\section{The effect of CRS treatment in quality of life}

CRS is a complex disease where multiple intrinsic and extrinsic factors interact, thus forming a wide spectrum of disease variants with diverse characteristics on clinical and pathophysiologic level ${ }^{(57)}$. Medical treatment, including nasal irrigation and anti-inflammatory agents (either systematic or local), is the first-line modality indicated in all cases. Surgical treatment is reserved when maximal medical treatment fails to provide a satisfactory outcome, as evaluated by objective and subjective measures ${ }^{(1,9)}$. CRS affects multiple aspects of QoL in variable manners, and no gold standards exist for its evaluation and treatment, especially when surgical interventions are planned.

\section{Medical treatment}

First-line medical treatment with nasal irrigations and intranasal corticosteroids (INCS) usually is administered by primary health care physicians, but refractory cases should be referred to an otolaryngologist ${ }^{(58)}$. There is no evidence to support the regular administration of topical antifungals, antibiotics, antihistamines and surfactant irrigations, while nasal decongestants may be used short-term complementary to INCS in patients with CRSWNP ${ }^{(59)}$. Also, there is no proven superiority of any INCS type, form of delivery (spray, aerosol, drops) or higher dosage for CRS treatment ${ }^{(60)}$. The long-term benefit of a short-course oral corticosteroid treatment is unclear ${ }^{(61)}$. Encouraging evidence exists for the usage of monoclonal antibodies (anti-lgE, anti-IL-5, anti-IL-4, anti-IL-13) in CRSwNP treatment and their beneficial effect on QoL, although more research is required in this field ${ }^{(62)}$. A recent meta-analysis suggests that appropriate medical treatment is associated with improved QoL in cases of nonrefractory disease and sustained improvement of QoL after sinus surgery ${ }^{(63)}$.

\section{Surgical treatment}

ESS has been a widely adopted therapeutic modality for CRS, especially in cases refractory to medical treatment, with variable long-term results ${ }^{(64)}$. Its beneficial effect on QoL appears to be more pronounced in patients with nasal polyposis and asthma $(65,66)$. Approximately $75 \%$ of patients with medically refractory CRS report sleep disturbances, and sinus surgery has been shown to offer improvement in this domain ${ }^{(67-69)}$. A recent prospective study ${ }^{(70)}$ showed that ESS significantly improved the HRQoL and decreased absenteeism in patients with either CRS phenotype. In select cases of CRSWNP, endoscopic polypectomy in clinic (EPIC) may offer comparable to traditional ESS QoL improvements ${ }^{(71)}$. Patients with cystic fibrosis (CF) may experience similar improvement in postoperative QoL ${ }^{(72)}$. Acetylsalicylic acid (ASA) intolerance and depression have been associated with poorer QoL outcomes after ESS, while previous sinus surgery and asthma are variably reported as either negative predictive factors or without significance on postoperative response to treatment ${ }^{(73)}$. Mucosal eosinophilia and increased IL-5 levels on nasal mucosa have been associated with greater disease severity and higher rates of revision surgery ${ }^{(73,74)}$. Likewise, patients with CRSWNP are more likely to recur and need reoperation ${ }^{(1)}$. In paediatric population, ESS is rarely performed compared to the adult population, yet is a viable option for selected cases. In CF, severe nasal polyposis, and allergic fungal sinusitis this treatment modality may offer marked benefits on patients' $\mathrm{QoL}{ }^{(1)}$. 


\section{Other parameters affecting QoL in CRS}

Co-morbidities should always be identified and treated accordingly, as they pose an obstacle for optimal therapeutic outcome and improvement of QoL. Based on the concept of "the unified airway", upper and lower respiratory tracts are both anatomically and functionally tightly related entities ${ }^{(20)}$. Thus, it has been supported that treating the upper airway results in alleviation of lower airway symptoms ${ }^{(1,75,76)}$. Patients with asthma and primary ciliary dyskinesia may benefit from ESS, achieving improved lung function, and better overall QoL ${ }^{(77)}$. The same is also true for other chronic pulmonary diseases, like CF ${ }^{(78)}$. While patients with nasal polyposis and coexisting asthma may enjoy better QoL after FESS, an algorithm for optimal individualized therapy has not been defined yet, nor which outcomes and measurement scales are required to properly assess the response to treatment of such populations ${ }^{(79)}$. AERD in patients with nasal polyposis (Samter's triad) may receive an additional benefit from FESS if aspirin desensitization is administered postoperatively ${ }^{(80)}$. Furthermore, nasal septum deviation and nasal valve area deformities may contribute to CRS symptoms and treating those deformities should always be taken into consideration to alleviate burden of CRS disease ${ }^{(81)}$.

Environmental factors may also have a detrimental effect on CRS severity and efficacy of sinus surgery. Small inhalant pollutants may contribute to non-allergic symptomatology in patients with and without nasal polyposis and lead to treatment failure due to undetected coexisting allergic or non-allergic rhinitis (NAR) ${ }^{(82)}$. This has been shown to be true even on the absence of rhinitis, especially in patients with CRSsNP, underlining the significant burden air pollutants pose on disease severity and progression, as well as on QoL ${ }^{(83)}$.

The psychological implication of CRS is a neglected field of research, although the emotional burden of the disease is far from negligible. General health assessment may be paramount for proper diagnosis and better comprehension of patients' needs, since the clinical picture may greatly differ from the patient's estimation of the disease and its symptoms ${ }^{(84)}$. Neither depression nor anxiety may be alleviated after FESS, despite significant improvement of disease specific objective and QoL measurements ${ }^{(85)}$. On the other hand, co-morbid anxiety is associated with reduced QOL improvement following ESS ${ }^{(86)}$.

For a variety of reasons, control of disease will fail in a considerable number of patients ${ }^{\left({ }^{87}\right)}$. Before the final diagnosis of a difficult-to-treat CRS / uncontrolled CRS / Severe Chronic Upper Airway Disease (SCUAD) is made, disease-unrelated factors such as patient adherence, inappropriate treatment or incorrect diagnosis must be identified and addressed accordingly ${ }^{(9)}$. SCUAD results in poor QoL, affects both children and adults, poses a high socioeconomic burden, and presents a difficult treatment challenge ${ }^{(88-91)}$. Clinical markers associated with SCUAD are presence of nasal polyps, asthma co-morbidity and AERD ${ }^{\text {(92) }}$.
A multitude of cellular, immunologic, genetic and molecular biomarkers are under investigation, to unravel the pathophysiologic profile of such patients and determine the optimal medical and/or surgical treatment ${ }^{(93,94)}$.

\section{Discrepancies and controversies}

The value of objective and subjective outcome assessment methods cannot be underestimated. Lately, there is a growing acceptance that patients' perspective on outcome is more important than objective assessment methods ${ }^{(95)}$. Towards this direction mobile technology is contributing to further help patients deal with CRS burden ${ }^{(96-98)}$. Furthermore, discrepancies do exist between objective and subjective measures of disease burden assessment. It has been shown that the Lund-Mackay score can provide information about the expected postoperative improvement of QoL after ESS, yet confined on certain SNOT-22 domains (rhinologic and extranasal) (99). For nasal polyposis, ESS has shown to offer significant improvement on SF-36 and VAS scores for mid-term periods ( 6 to 12 months) but worsened Lund-Kennedy endoscopic scores accordingly ${ }^{(100)}$. PNIF measurements tend to correlate well with QoL, especially with postoperative SNOT-22 questionnaire results, but not with the preoperative Lund-Mackay and Lund-Kennedy scales (101). Unexpectedly low score on PROM after ESS may be attributed to existing co-morbidities and should not necessarily be seen as a failure to reflect the burden of CRS. This has been proved in cases with concomitant obstructive sleep apnea (OSA) ${ }^{(102)}$. In view of such findings, patient selection based on traditional phenotype classification and measures of disease severity may not be adequate for defining the optimal treatment modality, either medical or surgical, underlining the need for novel criteria for state-of-the-art therapeutic interventions ${ }^{(103)}$.

Another issue to be addressed is that QoL is subjectively perceived, based on the unique way it is experienced by each individual. "Quantification" and "objectification" are not easy tasks; each PROM tool tries to interpret solely intrinsic procedures into measurable variables. Widely used and reliable questionnaires like SNOT-22, EQ5D and EQ5D-VAS detect otologic/facial pain and sleep-related problems as more prominent on CRS patients, underlining the differential effect of symptoms and underlying pathophysiologic mechanisms on QoL ${ }^{(104)}$. Strangely, generic QoL assessment tools, such as the General Well-Being Schedule (GWBS), may be more sensitive than disease- and symptomspecific PROMs for depicting the patient's perception of the disease and its treatment ${ }^{(105)}$. It is also prudent to acknowledge the significance of QoL assessment methodology, as shown by the response shift paradigm in sinus surgery outcomes ${ }^{(106,107)}$. Additionally, there is a trend to simplify evaluation of QoL in chronic upper airway diseases. In AR, VAS was found to correlate well with QoL measurement instruments such as RQLQ (Rhinoconjunctivitis Quality of Life Questionnaire) ${ }^{(75)}$. Likewise, VAS 
has been very recently shown to have a strong association with SNOT-22 in CRS patients ${ }^{(108)}$. Finally, the evaluation of PROM scores on QoL should be both longitudinal and cross-sectional, given the inhomogeneous profiles of patients suffering from CRS and the quite often encountered discrepancies between the statistical and clinical importance sinus surgery results ${ }^{(65)}$. Finally, as it has been clearly pointed out ${ }^{(109)}$, the heterogeneity of outcome assessment methodologies poses an obstacle on treatment effectiveness evaluation and comparison. Development and endorsement of core outcomes sets will facilitate future meta-analyses and increase the value of research on disease therapeutic approaches.

\section{Conclusion}

Chronic rhinosinusitis is still an unconquered domain, despite the plethora of objective and subjective measurements of disease severity. Current basic research aims at clarifying the underlying pathophysiologic mechanisms of the disease, since its classical phenotypic classification does not meet the needs of modern and individualized medicine. The results of this effort will possibly provide new ground for adaptation of current assessment methodologies of disease burden. Meanwhile, QoL outcome tools are continually under active investigation and refinement, technological evolution provides more accurate devices for diagnostic and therapeutic purposes, and the accumulation of surgical experience and innovations increases the efficiency and efficacy of the procedures. The combined breakthrough knowledge on these fields may obviate in the future the need of the term "uncontrolled rhinosinusitis".

\section{Acknowledgement}

None to declare.

\section{Authorship contribution}

DK: Writing - Original draft preparation; MD: Writing - Reviewing and Editing; AK: Writing - Reviewing and Editing; SV: Reviewing; AM: Writing - Original draft preparation; EP: Conceptualization, Methodology, Supervision, Writing - Reviewing and Editing.

\section{Conflict of interest}

None to declare.

\section{Ethics approval and consent to participate}

Not applicable.

\section{Consent for publication}

Not applicable.

\author{
Availability of data and materials \\ Not applicable.
}

\section{Funding}

Not applicable.
1. Fokkens WJ, Lund VJ, Mullol J, Bachert C Alobid I, Baroody F, et al. EPOS 2012 European position paper on rhinosinusitis and nasal polyps 2012. A summary for otorhinolaryngologists. Rhinology. 2012 Mar;50(1):1-12.

2. Beule A. Epidemiology of chronic rhinosinusitis, selected risk factors, comorbidities, and economic burden. GMS Curr Top Otorhinolaryngol Head Neck Surg. 2015:14:Doc11.

3. Campbell AP, Hoehle LP, Phillips KM Caradonna DS, Gray ST, Sedaghat AR Symptom control in chronic rhinosinusitis is an independent predictor of productivity loss. Eur Ann Otorhinolaryngol Head Neck Dis. 2018 Aug;135(4):237-241.

4. Erskine SE, Hopkins C, Clark A, Anari S, Robertson A, Sunkaraneni S, et al. Chronic rhinosinusitis and mood disturbance. Rhinology. 2017 Jun 1;55(2):113-9.

5. The impact of chronic airway disease on symptom severity and global suffering in Canadian rhinosinusitis patients [Internet]. 2018 [cited 2018 Jun 9]. Available from: https://www.ncbi.nlm.nih.gov/pmc/articles/PMC5975522/

6. Philpott C, Erskine S, Hopkins C, Coombes E, Kara N, Sunkareneni $\mathrm{V}$, et al. A case-control study of medical, psychological and socioeconomic factors influencing the severity of chronic rhinosinusitis. Rhinology. 2016 Jun;54(2):134-40.

7. Yip J, Vescan AD, Witterick IJ, Monteiro E. The personal financial burden of chronic rhinosinusitis: A Canadian perspective. Am Rhinol Allergy. 2017 Jul 1;31(4):216-21.

8. Saxena S, Orley J, WHOQOL Group. Quality of life assessment: The world health organization perspective. Eur Psychiatry. 1997;12 Suppl 3:263s-6s.

9. Hellings PW, Fokkens WJ, Akdis C, Bachert C, Cingi C, Dietz de Loos D, et al. Uncontrolled allergic rhinitis and chronic rhinosinusitis: where do we stand today? Allergy. 2013 Jan;68(1):1-7.

10. Rudmik L, Hopkins C, Peters A, Smith TL, Schlosser RJ, Soler ZM. Patient-reported outcome measures for adult chronic rhinosinusitis: A systematic review and quality assessment. J Allergy Clin Immunol. 2015 Dec;136(6):1532-1540.e2.

11. Hopkins C, Gillett S, Slack R, Lund VJ, Browne JP. Psychometric validity of the 22-item Sinonasal Outcome Test. Clin Otolaryngol. 2009 Oct;34(5):447-54.

12. CONSTITUTION of the World Health Organization. Chron World Health Organ.
1947:1(1-2):29-43.

13. Elkinton JR. Medicine and the quality of life. Ann Intern Med. 1966 Mar:64(3):711-4.

14. Spitzer WO, Dobson AJ, Hall J, Chesterman

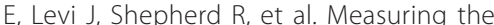
quality of life of cancer patients: a concise QL-index for use by physicians. J Chronic Dis. 1981;34(12):585-97.

15. Gill TM, Feinstein AR. A critical appraisal of the quality of quality-of-life measurements. JAMA. 1994 Aug 24;272(8):619-26.

16. Torrance GW. Utility approach to measuring health-related quality of life. J Chronic Dis. 1987;40(6):593-603

17. Garratt A, Schmidt L, Mackintosh A Fitzpatrick R. Quality of life measurement: bibliographic study of patient assessed health outcome measures. BMJ. 2002 Jun 15:324(7351):1417

18. Gray ST, Hoehle LP, Phillips KM, Caradonna DS, Sedaghat AR. Patient-reported control of chronic rhinosinusitis symptoms is positively associated with general healthrelated quality of life. Clin Otolaryngol. 2017 Dec;42(6):1161-6.

19. Hoehle LP, Phillips KM, Speth MM Caradonna DS, Gray ST, Sedaghat AR. Responsiveness and minimal clinically important difference for the EQ-5D in 
chronic rhinosinusitis. Rhinology. 2018 Sep 3:

20. Klimek L, Bergmann K-C, Biedermann T, Bousquet J, Hellings P, Jung K, et al. Visual analogue scales (VAS): Measuring instruments for the documentation of symptoms and therapy monitoring in cases of allergic rhinitis in everyday health care: Position Paper of the German Society of Allergology (AeDA) and the German Society of Allergy and Clinical Immunology (DGAKI), ENT Section, in collaboration with the working group on Clinical Immunology, Allergology and Environmental Medicine of the German Society of Otorhinolaryngology, Head and Neck Surgery (DGHNOKHC). Allergo I Int. 2017;26(1):16-24

21. Kennedy JL, Hubbard MA, Huyett P, Patrie JT, Borish L, Payne SC. Sino-nasal outcome test (SNOT-22): a predictor of postsurgical improvement in patients with chronic sinusitis. Ann Allergy Asthma Immunol. 2013 Oct;111(4):246-251.e2.

22. Garbutt J, Spitznagel E, Piccirillo J. Use of the modified SNOT-16 in primary care patients with clinically diagnosed acute rhinosinusitis. Arch Otolaryngol Head Neck Surg. 2011 Aug;137(8):792-7.

23. 23. DeConde AS, Mace JC, Bodner T, Hwang PH, Rudmik L, Soler ZM, et al. SNOT22 quality of life domains differentially predict treatment modality selection in chronic rhinosinusitis. Int Forum Allergy Rhinol. 2014 Dec;4(12):972-9.

24. de Dorlodot C, Horoi M, Lefebvre P, Collet $\mathrm{S}$, Bertrand B, Eloy P, et al. French adaptation and validation of the sino-nasal outcome test-22: a prospective cohort study on quality of life among 422 subjects. Clin Otolaryngol. 2015 Feb;40(1):29-35.

25. Lachanas VA, Tsea M, Tsiouvaka S, Hajiioannou JK, Skoulakis CE, Bizakis JG. The sino-nasal outcome test (SNOT)-22: validation for Greek patients. Eur Arch Otorhinolaryngol. 2014 Oct;271(10):2723-8.

26. Lange B, Thilsing T, Al-kalemji A, Baelum J, Martinussen T, Kjeldsen A. The SinoNasal Outcome Test 22 validated for Danish patients. Dan Med Bull. 2011 Feb;58(2):A4235.

27. Ware JE, Sherbourne CD. The MOS 36-item short-form health survey (SF-36). I. Conceptual framework and item selection. Med Care. 1992 Jun;30(6):473-83.

28. McHorney CA, Ware JE, Raczek AE. The MOS 36-Item Short-Form Health Survey (SF-36): II. Psychometric and clinical tests of validity in measuring physical and mental health constructs. Med Care. 1993 Mar;31(3):24763.

29. McHorney CA, Ware JE, Lu JF, Sherbourne CD. The MOS 36-item Short-Form Health Survey (SF-36): III. Tests of data quality, scaling assumptions, and reliability across diverse patient groups. Med Care. 1994 Jan;32(1):40-66.

30. van der Veen J, Seys SF, Timmermans M Levie P, Jorissen M, Fokkens WJ, et al. Real- life study showing uncontrolled rhinosinusitis after sinus surgery in a tertiary referral centre. Allergy. 2017 Feb;72(2):282-90.

31. Ference EH, Stubbs V, Lidder AK, Chandra RK, Conley D, Avila PC, et al. Measurement and comparison of health utility assessments in chronic rhinosinusitis. Int Forum Allergy Rhinol. 2015 Oct;5(10):929-36.

32. Andresen EM, Gravitt GW, Aydelotte ME, Podgorski CA. Limitations of the SF-36 in a sample of nursing home residents. Age Ageing. 1999 Oct;28(6):562-6.

33. Stewart MG, Witsell DL, Smith $T L$, Weaver EM, Yueh B, Hannley MT. Development and validation of the Nasal Obstruction Symptom Evaluation (NOSE) scale. Otolaryngol Head Neck Surg. 2004 Feb;130(2):157-63.

34. Lipan MJ, Most SP. Development of a severity classification system for subjective nasal obstruction. JAMA Facial Plast Surg. 2013 Oct;15(5):358-61.

35. Kahveci OK, Miman MC, Yucel A, Yucedag F, Okur E, Altuntas A. The efficiency of Nose Obstruction Symptom Evaluation (NOSE) scale on patients with nasal septal deviation. Auris Nasus Larynx. 2012 Jun;39(3):275-9.

36. van Zijl FVWJ, Timman R, Datema FR. Adaptation and validation of the Dutch version of the nasal obstruction symptom evaluation (NOSE) scale. Eur Arch Otorhinolaryngol. 2017 Jun;274(6):2469-76.

37. Ishii L, Godoy A, Ishman SL, Gourin CG, Ishii $M$. The nasal obstruction symptom evaluation survey as a screening tool for obstructive sleep apnea. Arch Otolaryngol Head Neck Surg. 2011 Feb;137(2):119-23.

38. Menegat F, Monnazzi MS, Silva BN, de Moraes M, Gabrielli M a. C, Pereira-Filho VA. Assessment of nasal obstruction symptoms using the NOSE scale after surgically assisted rapid maxillary expansion. Int J Oral Maxillofac Surg. 2015 Nov;44(11):1346-50.

39. Bezerra TFP, Piccirillo JF, Fornazieri MA, Pilan RR de M, Pinna F de R, Padua FG de $M$, et al. Assessment of quality of life after endoscopic sinus surgery for chronic rhinosinusitis. Braz J Otorhinolaryngol. 2012 Apr;78(2):96-102.

40. Macasaet MAV, Cruz ETS. Quality of Life after FESS among Patients with Nasal Polyps using the NOSE Questionnaire Translated in Filipino (NOSE-Ph). Philippine Journal of Otolaryngology Head and Neck Surgery. 2016;31(1):17-21.

41. Thomas AJ, Orlandi RR, Ashby S, Mace JC, Smith TL, Alt JA. Nasal obstruction has a limited impact on sleep quality and quality of life in patients with chronic rhinosinusitis. Laryngoscope. 2016;126(9):1971-6.

42. EuroQol Group. EuroQol--a new facility for the measurement of health-related quality of life. Health Policy. 1990 Dec;16(3):199208.

43. Remenschneider AK, D'Amico L, Gray ST, Holbrook EH, Gliklich RE, Metson R, The EQ-5D: a new tool for studying clini- cal outcomes in chronic rhinosinusitis. Laryngoscope. 2015 Jan;125(1):7-15.

44. Remenschneider AK, Scangas G, Meier JC, Gray ST, Holbrook EH, Gliklich RE, et al. EQ-5D-derived health utility values in patients undergoing surgery for chronic rhinosinusitis. Laryngoscope. 2015 May;125(5):1056-61.

45. Fu Q-L, Ma J-X, Ou C-Q, Guo C, Shen S-Q, Xu $G$, et al. Influence of self-reported chronic rhinosinusitis on health-related quality of life: a population-based survey. PLoS ONE. 2015;10(5):e0126881.

46. Kim DH, Han K, Kim SW. Effect of Chronic Rhinosinusitis With or Without Nasal Polyp on Quality of Life in South Korea: 5th Korea National Health and Nutrition Examination Survey Korean. Clin Exp Otorhinolaryngol. 2016 Jun;9(2):150-6.

47. Tarasidis GS, DeConde AS, Mace JC, Ashby S, Smith TL, Orlandi RR, et al. Cognitive dysfunction associated with pain and quality of life in chronic rhinosinusitis. Int Forum Allergy Rhinol. 2015 Nov;5(11):1004-9.

48. Mahdavinia M, Schleimer RP, Keshavarzian A. Sleep disruption in chronic rhinosinusitis. Expert Rev Anti Infect Ther. 2017;15(5):45765.

49. Banoub RG, Hoehle LP, Phillips KM Schulman BJ, Caradonna DS, Gray ST, et al. Depressed Mood Modulates Impact of Chronic Rhinosinusitis Symptoms on Quality of Life. J Allergy Clin Immunol Pract. 2018 Dec;6(6):2098-105.

50. Rowan NR, Soler ZM, Storck KA, Othieno F, Ganjaei KG, Smith TL, et al. Impaired eatingrelated quality of life in chronic rhinosinusitis. Int Forum Allergy Rhinol. 2018 Nov 28;

51. Speth MM, Hoehle LP, Phillips KM, Caradonna DS, Gray ST, Sedaghat AR. Changes in chronic rhinosinusitis symptoms differentially associate with improvement in general health-related quality of life. Ann Allergy Asthma Immunol. 2018 Aug;121(2):195-9.

52. Campbell AP, Phillips KM, Hoehle LP, Feng AL, Bergmark RW, Caradonna DS, et al. Depression symptoms and lost productivity in chronic rhinosinusitis. Ann Allergy Asthma Immunol. 2017;118(3):286-9.

53. Zhou S, Hur K, Shen J, Wrobel B. Impact of sinonasal disease on depression, sleep duration, and productivity among adults in the United States. Laryngoscope Investig Otolaryngol. 2017;2(5):288-94.

54. Smith KA, Ashby S, Orlandi RR, Oakley G, Alt $J A$. The price of pain in chronic rhinosinusitis. Int Forum Allergy Rhinol. 2018 Apr 12;

55. Phillips KM, Bergmark RW, Hoehle LP, Caradonna DS, Gray ST, Sedaghat AR. Chronic rhinosinusitis exacerbations are differentially associated with lost productivity based on asthma status. Rhinology. 2018 Dec; 56:(4):323-329.

56. Rudmik L. Economics of Chronic Rhinosinusitis. Curr Allergy Asthma Rep. 2017 Apr;17(4):20.

57. Akdis CA, Bachert C, Cingi C, Dykewicz 
MS, Hellings PW, Naclerio RM, et al. Endotypes and phenotypes of chronic rhinosinusitis: a PRACTALL document of the European Academy of Allergy and Clinical Immunology and the American Academy of Allergy, Asthma \& Immunology. J Allergy Clin Immunol. 2013 Jun;131(6):1479-90.

58. Sedaghat AR. Chronic Rhinosinusitis. Am Fam Physician. 2017 Oct 15;96(8):500-6.

59. Snidvongs K, Thanaviratananich S. Update on Intranasal Medications in Rhinosinusitis Curr Allergy Asthma Rep. 2017 Jul;17(7):47

60. Chong LY, Head K, Hopkins C, Philpott C, Burton MJ, Schilder AGM. Different types of intranasal steroids for chronic rhinosinusitis. Cochrane Database Syst Rev. 2016 Apr 26:4:CD011993

61. Head K, Chong LY, Hopkins C, Philpott C, Schilder AGM, Burton MJ. Short-course oral steroids as an adjunct therapy for chronic rhinosinusitis. Cochrane Database Syst Rev. 2016 Apr 26;4:CD011992.

62. Tsetsos N, Goudakos JK, Daskalakis D, Konstantinidis I, Markou K. Monoclonal antibodies for the treatment of chronic rhinosinusitis with nasal polyposis: a systematic review. Rhinology. 2018 Mar 1;56(1):11-21.

63. Patel ZM, Thamboo A, Rudmik L, Nayak JV, Smith $T L$, Hwang PH. Surgical therapy vs continued medical therapy for medically refractory chronic rhinosinusitis: a systematic review and meta-analysis. Int Forum Allergy Rhinol. 2017;7(2):119-27.

64. Shivakumar T, Sambandan AP. Retrospective analysis of the effectiveness of functiona endoscopic sinus surgery in the treatment of adult chronic rhinisinusitis refractory to medical treatment. Indian J Otolaryngol Head Neck Surg. 2011 Oct;63(4):321-4.

65. Zhang Z, Adappa ND, Doghramji LJ, Chiu AG, Lautenbach E, Cohen NA, et al. Quality of life improvement from sinus surgery in chronic rhinosinusitis patients with asthma and nasal polyps. Int Forum Allergy Rhinol. 2014 Nov;4(11):885-92.

66. Schlosser RJ, Smith TL, Mace J, Soler ZM. Asthma quality of life and control after sinus surgery in patients with chronic rhinosinusitis. Allergy. 2017 Mar;72(3):483-91.

67. Alt JA, Smith TL, Schlosser RJ, Mace JC, Soler ZM. Sleep and quality of life improvements after endoscopic sinus surgery in patients with chronic rhinosinusitis. Int Forum Allergy Rhinol. 2014 Sep;4(9):693-701.

68. Nguyen DT, Arous F, Gallet P, Felix-Ravelo M, Nguyen-Thi PL, Rumeau C, et al. Sinonasal symptom-related sleep disorders before and after surgery for nasal polyposis. Rhinology. 2017 Sep 1;55(3):262-8.

69. Värendh $M$, Johannisson $A$, Hrubos-Strøm $H$, Andersson M. Sleep quality improves with endoscopic sinus surgery in patients with chronic rhinosinusitis and nasal polyposis. Rhinology. 2017 Mar 1;55(1):45-52.

70. Sahlstrand-Johnson P, Hopkins C, Ohlsson B, Ahlner-Elmqvist M. The effect of endoscopic sinus surgery on quality of life and absenteeism in patients with chronic rhinosinuitis
- a multi-centre study. Rhinology. 2017 Sep 1;55(3):251-61.

71. Kilty SJ, Lasso A, Mfuna-Endam L, Desrosiers MY. Case-control study of endoscopic polypectomy in clinic (EPIC) versus endoscopic sinus surgery for chronic rhinosinusitis with polyps. Rhinology. 2018 Jun 1;56(2):155-7.

72. Khalid AN, Mace J, Smith TL. Outcomes of sinus surgery in adults with cystic fibrosis. Otolaryngol Head Neck Surg. 2009 Sep;141(3):358-63.

73. Adnane C, Adouly T, Zouak A, Mahtar M. Quality of life outcomes after functional endoscopic sinus surgery for nasal polyposis. Am J Otolaryngol. 2015 Feb;36(1):47-51.

74. Turner JH, Li P, Chandra RK. Mucus T helper 2 biomarkers predict chronic rhinosinusitis disease severity and prior surgical intervention. Int Forum Allergy Rhinol. 2018 Jun 8;

75. Brożek JL, Bousquet J, Agache I, Agarwal A, Bachert C, Bosnic-Anticevich S, et al. Allergic Rhinitis and its Impact on Asthma (ARIA) guidelines-2016 revision. J Allergy Clin Immunol. 2017 Oct;140(4):950-8.

76. Doulaptsi M, Steelant B, Hellings P. Treating the nose for controlling the lung: a vanishing story? In: The Nose and Sinuses in Respiratory Disorders. 2017. p. 177-92.

77. Alanin MC, Aanaes K, Høiby N, Pressler T, Skov M, Nielsen KG, et al. Sinus surgery can improve quality of life, lung infections, and lung function in patients with primary ciliary dyskinesia. Int Forum Allergy Rhinol. 2017;7(3):240-7

78. Khalfoun S, Tumin D, Ghossein M, Lind M, Hayes D, Kirkby S. Improved Lung Function after Sinus Surgery in Cystic Fibrosis Patients with Moderate Obstruction. Otolaryngol Head Neck Surg. 2018 Feb;158(2):381-5.

79. Rix I, Håkansson K, Larsen CG, Frendø M, von Buchwald C. Management of chronic rhinosinusitis with nasal polyps and coexisting asthma: A systematic review. Am J Rhinol Allergy. 2015 Jun;29(3):193-201.

80. Havel M, Ertl L, Braunschweig F, Markmann S, Leunig A, Gamarra F, et al. Sinonasal outcome under aspirin desensitization following functional endoscopic sinus surgery in patients with aspirin triad. Eur Arch Otorhinolaryngol. 2013 Feb;270(2):571-8.

81. Prasad S, Varshney S, Bist SS, Mishra S Kabdwal N. Correlation study between nasal septal deviation and rhinosinusitis. Indian J Otolaryngol Head Neck Surg. 2013 Dec:65(4):363-6.

82. Mady LJ, Schwarzbach HL, Moore JA, Boudreau RM, Kaffenberger TM, Willson TJ, et al. The association of air pollutants and allergic and nonallergic rhinitis in chronic rhinosinusitis. Int Forum Allergy Rhinol. 2018 Mar;8(3):369-76.

83. Mady LJ, Schwarzbach HL, Moore JA Boudreau RM, Willson TJ, Lee SE. Air pollutants may be environmental risk factors in chronic rhinosinusitis disease progression. Int Forum Allergy Rhinol. 2018 Mar:8(3):377-84.
84. Wardas P, Markowski J, Piotrowska-Seweryn A, Slaska-Kaspera A, Latacz B, Kołodziej W. Impact of rhinosinusitis symptoms on patients' self-esteem before and after FESS. Otolaryngol Pol. 2014 Dec;68(6):293-7.

85. Adams KN, Schuman TA, Ebert CS, You W Tomoum MO, Senior BA. Self-reported anxiety and depression are unchanged after endoscopic sinus surgery for chronic rhinosinusitis. Rhinology. 2018 Sep;56(3):234240.

86. Steele TO, Mace JC, Smith TL. Does comorbid anxiety predict quality of life outcomes in patients with chronic rhinosinusitis following endoscopic sinus surgery? Int Forum Allergy Rhinol. 2015 Sep;5(9):829-38.

87. Prokopakis E, Vlastos I, Pant H, Ferguson BJ. Chronic rhinosinusitis: observation or treatment. Curr Opin Allergy Clin Immunol. 2013 Feb;13(1):31-6.

88. WHO Collaborating Center for Asthma and Rhinitis, Bousquet J, Anto JM, Demoly P, Schünemann HJ, Togias A, et al. Severe chronic allergic (and related) diseases: a uniform approach--a MeDALL--GA2LEN--ARIA position paper. Int Arch Allergy Immunol. 2012;158(3):216-31.

89. Prokopakis EP, Vlastos IM, Ferguson BJ, Scadding G, Kawauchi H, Georgalas C, et al. SCUAD and chronic rhinosinusitis. Reinforcing hypothesis driven research in difficult cases. Rhinology. 2014 Mar;52(1):38.

90. Karatzanis A, Kalogjera L, Scadding G, Velegrakis S, Kawauchi H, Cingi C, et al. Severe Chronic Upper Airway Disease (SCUAD) in children. Definition issues and requirements. Int J Pediatr Otorhinolaryngol. 2015 Jul;79(7):965-8.

91. Prokopakis EP, Kalogjera L, Karatzanis AD. Pediatric Severe Chronic Upper Airway Disease (P-SCUAD). Curr Allergy Asthma Rep. 2015 Dec;15(12):68.

92. López-Chacón M, Mullol J, Pujols L. Clinical and biological markers of difficult-to-treat severe chronic rhinosinusitis. Curr Allergy Asthma Rep. 2015 May;15(5):19.

93. De Greve G, Hellings PW, Fokkens WJ, Pugin B, Steelant B, Seys SF. Endotype-driven treatment in chronic upper airway diseases. Clin Transl Allergy. 2017;7:22.

94. Avdeeva K, Fokkens W. Precision Medicine in Chronic Rhinosinusitis with Nasal Polyps. Curr Allergy Asthma Rep. 2018 Mar 24;18(4):25.

95. Hopkins C, Philpott C, Crowe S, Regan S, Degun A, Papachristou l, et al. Identifying the most important outcomes for systematic reviews of interventions for rhinosinusitis in adults: working with Patients, Public and Practitioners. Rhinology. 2016 Mar;54(1):206.

96. Seys SF, Bousquet J, Bachert C, Fokkens WJ, Agache I, Bernal-Sprekelsen M, et al. mySinusitisCoach: patient empowerment in chronic rhinosinusitis using mobile technology. Rhinology. 2018 Sep 1;56(3):209-15.

97. Caimmi D, Baiz N, Tanno LK, Demoly P, 
Arnavielhe S, Murray R, et al. Validation of the MASK-rhinitis visual analogue scale on smartphone screens to assess allergic rhinitis control. Clin Exp Allergy. 2017 Dec;47(12):1526-33.

98. Hellings PW, Akdis CA, Bachert C, Bousquet $J$, Pugin B, Adriaensen $G$, et al. EUFOREA Rhinology Research Forum 2016: report of the brainstorming sessions on needs and priorities in rhinitis and rhinosinusitis. Rhinology. 2017 Sep 1;55(3):202-10

99. Brooks SG, Trope M, Blasetti M, Doghramji L, Parasher A, Glicksman JT, et al. Preoperative Lund-Mackay computed tomography score is associated with preoperative symptom severity and predicts quality-of-life outcome trajectories after sinus surgery. Int Forum Allergy Rhinol. 2018 Jun;8(6):668675.

100. Djukic V, Dudvarski Z, Arsovic N, Dimitrijevic $M$, Janosevic L. Clinical outcomes and quality of life in patients with nasal polyposis after functional endoscopic sinus surgery. Eur Arch Otorhinolaryngol. 2015 Jan;272(1):83-9.

101. Whitcroft KL, Andrews PJ, Randhawa PS Peak nasal inspiratory flow correlates with quality of life in functional endoscopic sinus surgery. Clin Otolaryngol. 2017 Dec;42(6):1187-92.

102. Tajudeen BA, Brooks SG, Yan CH, Kuan EC, Schwartz JS, Suh JD, et al. Quality-of-life improvement after endoscopic sinus sur- gery in patients with obstructive sleep apnea. Allergy Rhinol (Providence). 2017 Mar 1;8(1):25-31.

103. Adnane C, Adouly T, Khallouk A, Rouad $S$, Abada R, Roubal $M$, et al. Using preoperative unsupervised cluster analysis of chronic rhinosinusitis to inform patient decision and endoscopic sinus surgery outcome. Eur Arch Otorhinolaryngol. 2017 Feb;274(2):879-85.

104. Hoehle LP, Phillips KM, Bergmark RW, Caradonna DS, Gray ST, Sedaghat AR. Symptoms of chronic rhinosinusitis differentially impact general health-related quality of life. Rhinology. 2016 Dec 1;54(4):31622.

105. Nordin S, Olsson P, Hedén Blomqvist E, Stjärne P, Ehnhage A, NAF2S2 Study Groupt. Effects of FESS and additional fluticasone propionate nasal drops on psychological well-being in nasal polyposis with asthma. Acta Otolaryngol. 2013 Sep;133(9):939-43.

106. Liu JJ, Davis GE. The significance of response shift in sinus surgery outcomes. Int Forum Allergy Rhinol. 2015 Jan;5(1):55-9.

107. Scadding G, Bousquet J, Bachert C, Fokkens WJ, Hellings PW, Prokopakis E, et al. Rhinology future trends: 2017 EUFOREA debate on allergic rhinitis. Rhinology. 2018 Jul 27;

108. Doulaptsi M, Prokopakis E, Seys S, Pugin B, Steelant B, Hellings P. Visual analogue scale for sino-nasal symptoms severity correlates with sino-nasal outcome test 22: paving the way for a simple outcome tool of CRS burden. Clin Transl Allergy. 2018;8:32.

109. Hopkins C, Hettige R, Soni-Jaiswal A, Lakhani R, Carrie S, Cervin A, et al. CHronic Rhinosinusitis Outcome MEasures (CHROME), developing a core outcome set for trials of interventions in chronic rhinosinusitis. Rhinology. 2018 Mar 1;56(1):22-32.

Emmanuel Prokopakis

Assoc. Professor

Department of Otorhinolaryngology

- Head and Neck Surgery

University of Crete School of Medi-

cine

University Avenue, Heraklion

71100 Crete

Greece

Tel: +30 6932237622

E-mail: eprokopakis@gmail.com

ISSN: 2589-5613 / O2019 The Author(s). This work is licensed under a Creative Commons Attribution 4.0 International License. The images or other third party material in this article are included in the article's Creative Commons license, unless indicated otherwise in the credit line; if the material is not included under the Creative Commons license, users will need to obtain permission from the license holder to reproduce the material. To view a copy of this license, visit http://creativecommons.org/licenses/by/4.0/ 